\title{
Modeled larval fish prey fields and growth rates help predict recruitment success of cod and anchovy in the North Sea
}

\author{
Klaus B. Huebert ${ }^{1,2, *}$, Johannes Pätsch ${ }^{3}$, Marc Hufnagl $^{1}$, Markus Kreus ${ }^{1,3,4}$, \\ Myron A. Peck ${ }^{1}$ \\ ${ }^{1}$ Institute for Hydrobiology and Fisheries Science, Center for Earth System Research and Sustainability, \\ University of Hamburg, 22767 Hamburg, Germany \\ ${ }^{2}$ Horn Point Laboratory, University of Maryland Center for Environmental Science, Cambridge, Maryland 21613, USA \\ ${ }^{3}$ Institute of Oceanography, Center for Earth System Research and Sustainability, University of Hamburg, 20146 Hamburg, \\ Germany \\ ${ }^{4}$ Present address: Federal Waterways Engineering and Research Institute, 22559 Hamburg, Germany
}

\begin{abstract}
We introduce a new, coupled modeling approach for simulating ecosystem-wide patterns in larval fish foraging and growth. An application of the method reveals how interplay between temperature and plankton dynamics during 1970-2009 impacted a cold-water species (Atlantic cod Gadus morhua) and a warm-water species (European anchovy Engraulis encrasicolus) in the North Sea. Larval fish growth rates were estimated by coupling models depicting traitbased foraging and bioenergetics of individuals, spatiotemporal changes in their prey field, and the biogeochemistry and hydrodynamics of the region. The biomass composition of modeled prey fields varied from $89 \%$ nano-, $10 \%$ micro-, and $1 \%$ mesoplankton to $15 \%$ nano-, $20 \%$ micro-, and $65 \%$ mesoplankton. The mean slope of the normalized biomass size spectrum was near -1.2 , consistent with theoretical and empirical estimates. Median larval fish growth rates peaked in June for $\operatorname{cod}\left(24 \% \mathrm{~d}^{-1}\right)$ and in July for anchovy $\left(17 \% \mathrm{~d}^{-1}\right)$. Insufficient prey resources played a substantial role in limiting the growth rates of cod larvae. Anchovy were consistently limited by cold temperatures. Faster median larval growth during specific months was significantly $(p<0.05)$ positively associated with detrended (i.e. higher than expected) juvenile recruitment indices in cod (rank correlation Kendall's tau $=22 \%$ ) and anchovy (tau $=42 \%$ ). For cod, the most predictive month was February, which was also when food limitation was most prevalent. The continued development of modeling tools based on first principles can help further a mechanistic understanding of how changes in the environment affect the productivity of living marine resources.
\end{abstract}

KEY WORDS: Fish larvae $\cdot$ Plankton $\cdot$ Model $\cdot$ Bottom-up processes $\cdot$ Prey availability $\cdot$ Growth $\cdot$ Recruitment $\cdot$ Cod $\cdot$ Anchovy $\cdot$ North Sea

\section{INTRODUCTION}

Climate change is altering the suitability of ocean habitats for marine flora and fauna (Pörtner et al. 2014), and the North Sea is one of 24 ecosystems designated as 'hot spots' of warming (Hobday \& Pecl 2014). North Sea water temperature has risen dra-

${ }^{*}$ Corresponding author: khuebert@umces.edu matically over the past several decades (MacKenzie \& Schiedek 2007, Huthnance et al. 2016) and is projected to warm another 1 to $3^{\circ} \mathrm{C}$ by the end of the century (Schrum et al. 2016). Many North Sea fishes have already exhibited important shifts in distribution and abundance, which have been correlated to historical changes in ocean climate (Perry 2005, restricted. Authors and original publication must be credited. 
Rijnsdorp et al. 2009, Simpson et al. 2011). For example, Simpson et al. (2011) analyzed survey data on 50 abundant Northeast Atlantic continental shelf species and concluded that the distribution or abundance of $72 \%$ of these species had changed in response to warming.

Within specific regions, the most dramatic responses to warming should be expected for species near their low or high latitudinal limits of distribution. Examples of this in the North Sea include the sub-Arctic to temperate Atlantic cod Gadus morhua and the temperate to sub-tropical European anchovy Engraulis encrasicolus, which have displayed opposite trends in productivity and distribution as this shelf sea has warmed. On the one hand, cod recruitment is lower when winter and spring conditions in the North Sea are warmer (Brander \& Mohn 2004, Drinkwater 2005), and cod biomass in this region has declined by $\sim 75 \%$ since a peak in the early 1970 s (Engelhard et al. 2014). On the other hand, anchovy thrive in warmer conditions, and their number in the North Sea has increased by orders of magnitude since the early 1990s (Beare et al. 2004, Alheit et al. 2012, Petitgas et al. 2012). Whereas cod has been heavily exploited for many decades, potentially exacerbating population responses to climate perturbations (Ottersen et al. 2006, Perry et al. 2010, Planque et al. 2010), European anchovy is not (yet) heavily fished in the North Sea.

The growth and survival of fish during early life history stages play an important role in shaping fish populations, and depend on the spatiotemporal dynamics of their environment with respect to bottom-up processes (e.g. slow growth due to insufficient food), top-down processes (e.g. predation mortality), and transport processes (e.g. advection beyond suitable habitat) (Houde 2008, Peck et al. 2012). Since all of the above processes can be affected by climate change, there is a great interest in understanding how fish larvae will fare under future climate conditions (Llopiz et al. 2014). Depending on the relative balance of bottom-up, top-down, and transport processes, models representing (a subset of) key mechanisms can be useful as tools to study and potentially forecast fish recruitment success (Peck \& Hufnagl 2012, Llopiz et al. 2014). In this study, which focuses on improving how bottom-up processes are modeled, we apply a new method for incorporating highly resolved and spatiotemporally dynamic size distributions of larval fish prey into such models.

Several previous studies have modeled ecosystemwide patterns of larval fish foraging and growth by coupling spatially explicit NPZ+ models (nutrientphytoplankton-zooplankton plus additional components such as detritus, the microbial loop, or multiple $\mathrm{P}$ or $\mathrm{Z}$ groups) to larval fish individual-based models (IBMs). Models have depicted prey fields of larval fish using different levels of complexity. Xu et al. (2013) simulated prey consumption by the larvae of Peruvian anchovy E. ringens feeding on 4 generic groups of phytoplankton and zooplankton, while, in a more complex example, Hinckley et al. (2009) included 13 developmental stages of an important copepod (Pseudocalanus sp.) to better resolve the prey fields of larval walleye pollock Theragra chalcogramma in the Gulf of Alaska. An intermediate approach has been to use (static) size spectra to disaggregate estimates of plankton biomass from a few large functional groups into many smaller size bins. Daewel et al. (2008a, 2015) simulated the feeding, growth, and potential survival of European sprat Sprattus sprattus and cod larvae in the North Sea by separating bulk zooplankton biomass estimates from an NPZ+ model into 36 size bins based on the average zooplankton size distribution observed in their study area (Daewel et al. 2008b).

In aquatic ecosystems, small plankton are much more abundant than large plankton, and the pioneering fieldwork by Sheldon et al. (1972) demonstrated that the combined volume of co-occurring particles among logarithmically spaced size ranges is 'roughly similar,' meaning simply that histograms of the amount of particles using log(size) bins are relatively flat. Idealized as mathematically integrable 'normalized size spectra' sensu Platt \& Denman $(1977,1978)$, such data have linear relationships between the logarithm of the normalized amount of particles (by volume, mass, sampling frequency, or probability of occurrence) and the logarithm of particle size (by volume, mass, length, etc.). On theoretical and empirical grounds, the log-log slope for size spectra of normalized biomass vs. individual biomass (NBSS slope) is expected to be near -1.2 (Platt \& Denman 1977, 1978, Kerr \& Dickie 2001, Jennings \& Mackinson 2003). Among other factors, seasonal pulses of plankton productivity cause variability in the NBSS slope (Rodriguez et al. 1987). In a previous application of the Quirks larval fish model, low-resolution plankton samples were used to construct high-resolution prey fields of NBSS slope -1.2, which yielded quite accurate predictions of in situ growth rates (Huebert \& Peck 2014). Nevertheless, even small changes to the NBSS slope can dramatically affect larval foraging success and growth rates (Huebert \& Peck 2014). Therefore, we did not choose an a priori value of -1.2 for the 
present study, but rather sought a way to model size spectra case by case from NPZ+ plankton data.

We introduce a practical approach for using NPZ+ model output of relatively low biological resolution (e.g. $2 \mathrm{P}$ and $2 \mathrm{Z}$ groups) to model larval fish prey fields that are: (1) spatiotemporally dynamic with respect to plankton size distribution and total biomass; (2) of arbitrarily high size resolution; (3) based on size spectrum theory. We applied the resulting size spectrum model to couple the North Sea NPZ+ model ECOHAM to the larval fish model Quirks and hindcast monthly growth rates of larval cod and anchovy in the North Sea from 1970 to 2010. After comparing growth rates of larvae predicted by our model to published empirical observations, we tested whether interannual variability in modeled larval growth is predictive of juvenile recruitment variability. Finally, we discuss the benefits of our dynamic prey biomass size spectrum model over alternative approaches.

\section{METHODS}

\section{Models}

Three of the models coupled in the present study (Quirks, ECOHAM, and HAMSOM) have been thoroughly described elsewhere (Pohlmann 1996, Lorkowski et al. 2012, Huebert \& Peck 2014). In brief, Quirks is an IBM of larval fish foraging behavior and growth physiology. Generic by design, Quirks can simulate very different types of larvae (characterized by 16 biological traits) and has been validated across a wide range of environmental conditions (Huebert \& Peck 2014). Published parameterizations for young Atlantic cod and European anchovy larvae (Table 1) typically yield growth rates differing by $5 \pm 6 \% \mathrm{~d}^{-1}$ (mean $\pm \mathrm{SD}$ ) from field or laboratory estimates (Huebert \& Peck 2014). The ecosystem model ECOHAM was designed to study carbon and nutrient cycling in the northwest continental European shelf including the North Sea (Pätsch \& Kühn 2008, Kühn et al. 2010, Lor- kowski et al. 2012). ECOHAM combines the hydrodynamic model HAMSOM (Backhaus 1985, Pohlmann 1996) for advective flow, turbulent mixing, temperature, and salinity with a biogeochemical module (Pätsch \& Kühn 2008, Kühn et al. 2010, Lorkowski et al. 2012) for C, N, P, Si, and O fluxes. ECOHAM depicts 2 phytoplankton (flagellates and diatoms) and 2 zooplankton (micro- and mesozooplankton) groups. Modeled temperatures are generally very realistic (Pohlmann 2006, Pätsch \& Kühn 2008). Spatiotemporal patterns of modeled phytoplankton and zooplankton biomass are reasonably consistent with available field observations, although model predictions for the winter are often too high (Pätsch \& Kühn 2008, Stegert et al. 2009).

\section{Quirks parameterization}

The foraging and growth of young, exogenously feeding $7 \mathrm{~mm}$ standard length (SL) cod and $5.5 \mathrm{~mm}$ SL anchovy was modeled using larval fish traits (Table 1) from Huebert \& Peck (2014). Based on spawning seasons (Munk \& Nielsen 2005), egg development (Regner 1996, Geffen \& Nash 2012), larval growth (Regner 1996, Otterlei et al. 1999, Huebert \& Peck 2014), and field samples (Nielsen \& Munk 2004, Kanstinger \& Peck 2009), we estimated that $7 \mathrm{~mm}$ cod and $5.5 \mathrm{~mm}$ anchovy larvae occur in the North Sea from early February to mid-June, and mid-June to late September, respectively. We modeled larval growth during these periods using monthly mean

Table 1. Larval fish parameterization and Quirks model sensitivity for cod and anchovy larvae in the North Sea. Sensitivity was defined as the maximum factor by which small relative changes to parameters were amplified and propagated to modeled prey requirement (Huebert \& Peck 2014). L: standard length $(\mathrm{mm}) ; M$ : dry mass $(\mu \mathrm{g}) ; R$ : routine respiration $\left(\mu \mathrm{g} \mathrm{h}^{-1}\right)$

\begin{tabular}{|lcccc|}
\hline Trait & Unit & Cod & Anchovy & Sensitivity \\
\hline Radius of cylindrical visual field & $\% L$ & 60 & 60 & 2.13 \\
Metabolic efficiency & $\%$ & 67.50 & 67.50 & 1.16 \\
Body shape $\left(M: L^{3}\right)$ & $\mu g \mathrm{~mm}^{-3}$ & 1.040 & 0.226 & 1.06 \\
Swimming speed & $\% L \mathrm{~s}^{-1}$ & 75 & 75 & 1.02 \\
Maximum digestion at $10^{\circ} \mathrm{C}$ & $\% \mathrm{M} \mathrm{h}^{-1}$ & 2.50 & 2.50 & 0.86 \\
Routine respiration at $10^{\circ} \mathrm{C}$ & $\% M \mathrm{~h}^{-1}$ & 0.20 & 0.41 & 0.85 \\
Maximum prey length & $\% L$ & 15.70 & 8.05 & 0.70 \\
Initial standard length (yolk depletion $+2 \mathrm{~mm})$ & $\mathrm{mm}$ & 7.0 & 5.5 & 0.52 \\
Cost of daytime foraging activity & $\% R$ & 200 & 200 & 0.49 \\
Temperature dependence of respiration $\left(Q_{10}\right)$ & & 2.38 & 1.39 & 0.45 \\
Prey length detected $50 \%$ of the time & $\mathrm{mm}$ & 0.07 & 0.07 & 0.42 \\
Maximum turbulent velocity of prey pursuit & $\% L \mathrm{~s}^{-1}$ & 100 & 100 & 0.36 \\
Temperature dependence of digestion $\left(Q_{10}\right)$ & & 2.5 & 2.5 & 0.35 \\
Encounter distance & $\% L$ & 50 & 50 & 0.10 \\
Prey pursuit/handling time & $\mathrm{s}$ & 1.5 & 1.5 & 0.10 \\
Upper thermal tolerance & ${ }^{\circ} \mathrm{C}$ & 15 & 25 & 0.00 \\
\hline
\end{tabular}


conditions, at the ECOHAM horizontal resolution of $\sim 20 \mathrm{~km}\left(\Delta \lambda=1 / 3^{\circ}, \Delta \Phi=1 / 5^{\circ}\right)$, and including the entire North Sea, without considering adult spawning locations or egg and larval transport. Prey fields were depicted as concentrations of plankton in $0.01 \mathrm{~mm}$ length bins from $0.02 \mathrm{~mm}$ to beyond the size that modeled larvae could successfully capture. The Quirks model was updated (version 1.01, https://sourceforge. net/projects/larvalfishquirks) to include microplankton prey $<0.04 \mathrm{~mm}$. The allometric equation for prey dry mass was revised (see Eq. A3 in the Appendix) to better match small protist plankton (Menden-Deuer \& Lessard 2000), and the equation for prey detection was changed to render nanoplankton $(<0.02 \mathrm{~mm})$ invisible while keeping the model parameter for prey detected $50 \%$ of the time at $0.07 \mathrm{~mm}$. Prey biomass and NBSS slope were modeled (see next section) using monthly mean $0-15 \mathrm{~m}$ depth ECOHAM plankton carbon (Lorkowski et al. 2012) converted to dry mass assuming a carbon content of $45 \%$. To obtain conservative (low) estimates for the influence of prey fields on growth and for consistency with Huebert \& Peck (2014), we assumed that larvae could vertically move to the surface mixed layer to feed, and that turbidity was negligible. The mean properties of the upper $15 \mathrm{~m}$, which included the peak plankton biomass concentration $\sim 93 \%$ of the time and had a thermocline only $\sim 1 \%$ of the time, served as an approximation of the surface mixed layer. To isolate the effects of dynamic prey size distributions on fish larvae, we ran additional Quirks simulations bypassing the size spectrum model and instead using a fixed NBSS slope value of -1.2 . Temperatures were taken from HAMSOM, as integrated into ECOHAM. Day length was calculated from latitude and mid-month date using the NOAA solar calculator implemented in the R package 'maptools.' Turbulent kinetic energy dissipation rate was set to $10^{-7} \mathrm{~W} \mathrm{~kg}^{-1}$ as in Huebert \& Peck (2014).

\section{Plankton biomass size spectrum model}

The biomass distribution among 4 ECOHAM plankton groups (flagellates, diatoms, micro-, and mesozooplankton) was used to construct plankton prey fields suitable as input for larval foraging as depicted by Quirks (size range, total biomass concentration, and NBSS slope). Although ECOHAM defines plankton functional groups by their trophodynamic role and not their size, an implicit size structure exists among the 4 functional groups. Flagellates are the smallest (unlike diatoms, they are small enough to be consumed by microzooplankton) while mesozooplankton have the largest body size (unlike microzooplankton, they are large enough to consume diatoms). Conventional length-based definitions for nanoplankton $(0.002-0.02 \mathrm{~mm})$, microplankton $(0.02-$ $0.2 \mathrm{~mm})$, and mesoplankton $(0.2-20 \mathrm{~mm})$ were assumed (Sieburth et al. 1978). Specifically, we assigned flagellates, diatoms, and microzooplankton a pooled length range of $0.002-0.2 \mathrm{~mm}$, and mesozooplankton a range of $0.2-20 \mathrm{~mm}$.

Our size spectrum model uses the plankton biomass of 2 different size ranges to calculate the NBSS slope that is theoretically consistent with this biomass distribution. For any 2 size ranges with plankton biomass $>0$, there exists exactly 1 such slope. The Appendix explains how we performed the calculations using mesoplankton $(0.2-20 \mathrm{~mm})$, total plankton (0.002-20 mm), and an empirical allometric relationship between length and dry mass. The same equations are equally valid for any other combination of 2 size ranges: separate, adjacent, or overlapping.

The following example serves to illustrate how and why the size spectrum model was coupled to the other models, using the case of $5.5 \mathrm{~mm}$ anchovy larvae at $57^{\circ} \mathrm{N}$ and $7.5^{\circ} \mathrm{E}$ in August 2004. For this time and place, mean temperature was $18^{\circ} \mathrm{C}$ (HAMSOM), mean total plankton biomass concentration was $400 \mu \mathrm{g} \mathrm{l}^{-1}$ (ECOHAM), and turbulent kinetic energy dissipation rate was assumed to be $10^{-7} \mathrm{~W} \mathrm{~kg}^{-1}$ (Huebert \& Peck 2014). In 1-hourly model time steps, each larva searches a volume of $\sim 0.5 \mathrm{l}$ for prey, and must consume and digest only $2.0 \mu \mathrm{g}, \sim 1 \%$ of the plankton dry mass present in that volume, to achieve its maximum growth (Quirks). However, some prey are too small for visual detection, some are too large for ingestion, and even optimal prey are only successfully observed, pursued, and captured $<40 \%$ of the time. The fraction of total plankton biomass that potentially benefits larvae depends on the NBSS slope. For the chosen month and location, the ratio of meso- to total plankton is $13.5 \%$ (ECOHAM). The size spectrum model converts this to a slope of -1.16 (Appendix). These conditions facilitate larvae foraging up to $9.2 \mu \mathrm{g} \mathrm{h}^{-1}$ (62\% of prey biomass too small for detection, $9 \%$ too large for capture, $16 \%$ suitable but not observed, $4 \%$ observed but not worth pursuit, $2 \%$ lost to turbulence, $3 \%$ escaped, and $4 \%$ potentially captured) and no food limitation (Quirks). Note that a steeper slope of -1.5 would have yielded an unfavorable prey field, reduced consumption of $1.7 \mu \mathrm{g} \mathrm{h}^{-1}$ (94\% of prey biomass too small for detection, $4 \%$ suitable but not observed, $<1 \%$ lost to other factors, and $<1 \%$ potentially captured) and food-limited growth. 


\section{Empirical data}

To validate model predictions, we compared modeled larval fish growth rates to published empirical measurements. Furthermore, we quantified the rank correlation between median modeled larval growth rates in year $x$ and juvenile recruitment indices in year $x+1$. Our recruitment indices were based on data from the first quarter, North Sea International Bottom Trawl Survey (NS-IBTS Q1) provided by ICES (datras.ices.dk). For cod, we used $\log _{10}$ age-1 catch per unit effort. For anchovy, no ecosystem-wide or age-specific data were available. Variability in NS-IBTS Q1 anchovy abundance was mostly driven by their presence/absence in different ICES subareas and years, as opposed to patterns in their density when present. Consequently, we used the square root of the proportion of sampled subareas where anchovy up to $15 \mathrm{~cm}$ in length were recorded as an index of recruitment. Anchovy are generally $<15 \mathrm{~cm}$ at age-1 and $>15 \mathrm{~cm}$ at age-2+ in the North Sea (Petitgas et al. 2012), thus the presence of these small individuals (independent of their sexual maturity) is indicative of juvenile recruitment. Data were aggregated by length-class for NS-IBTS 'standard species' and ICES subarea excluding areas 9 (Kattegat) and 10 (English Channel) and any subareas with <30 yr of survey data or where no small anchovy catches from 1971 to 2010 were reported. It is possible that some surveys did not consistently record anchovy data until 1988. Since dramatic long-term trends were apparent, both raw and detrended time-series were considered, with residuals relative to smoothed raw indices ( $\mathrm{R}$ function 'smooth.spline') serving as detrended indices. These residuals were approximately normally distributed for both species. All data analyses were conducted using R (R Development Core Team 2016). All maps were generated using data provided (marineregions.org) by the Flanders Marine Institute (VLIZ 2015).

\section{RESULTS}

\section{Prey fields}

The mean composition of modeled plankton biomass was $35 \%$ flagellates, $28 \%$ diatoms, $24 \%$ microzooplankton, and $13 \%$ mesozooplankton (Fig. 1). The mean modeled NBSS slope was -1.17 (Fig. 2). In $95 \%$ of the $>500000$ cases, the NBSS slope was between -1.29 and -1.09 , which corresponds to a range of approximately 4 to $26 \%$ mesozooplankton (Fig. 2,

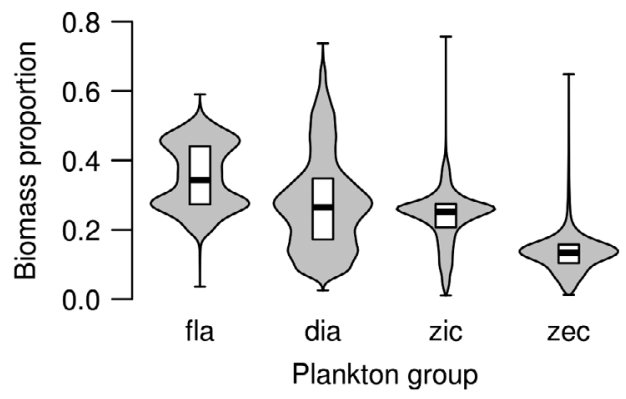

Fig. 1. Distribution of modeled North Sea plankton biomass (monthly means for 0-15 m depth, $20 \mathrm{~km}$ horizontal resolution, hindcast for 1970-2009, $\mathrm{n}=537600$ ) among 4 functional groups of the ECOHAM ecosystem model (fla: flagellates, dia: diatoms, zic: microzooplankton, zec: mesozooplankton). The minimum, 25th percentile, median, 75th percentile, maximum, and smoothed density distribution are indicated

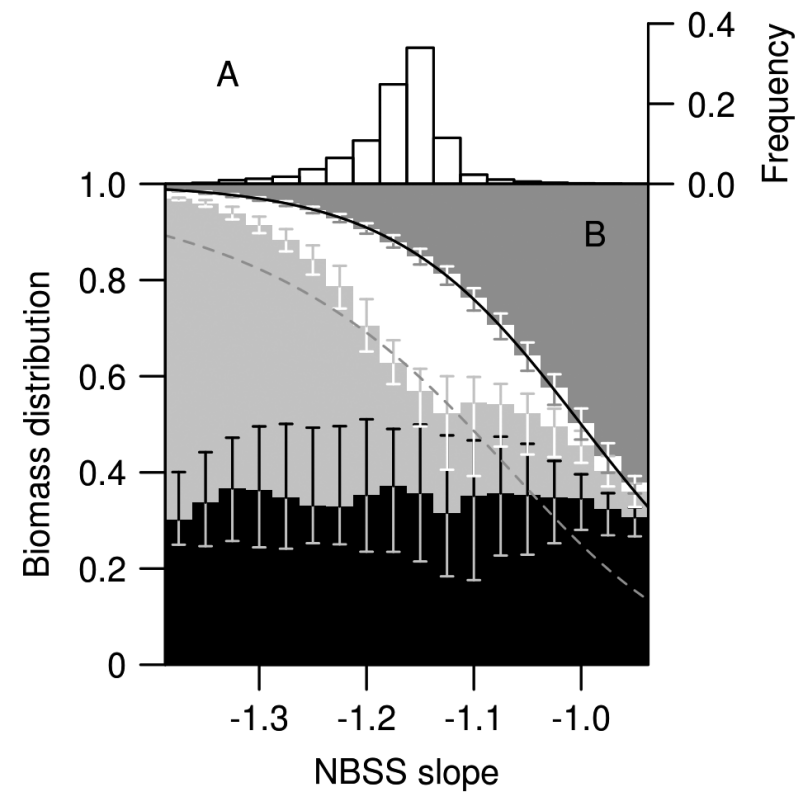

Fig. 2. (A) Frequency and (B) cumulative distributions of normalized biomass size spectrum (NBSS) slopes calculated from modeled North Sea plankton (monthly means for 0$15 \mathrm{~m}$ depth, $20 \mathrm{~km}$ horizontal resolution, hindcast for 1970$2009, \mathrm{n}=537600$ ). The theoretical distribution for this range of NBSS slopes varied from mostly mesoplankton at shallow slopes (above solid line, Eq. A6 in the Appendix), to mostly nanoplankton at steep slopes (below dashed line, Eq. A6 adapted for nanoplankton), with up to $28 \%$ microplankton at a slope of $-1.075(0.02-0.2 \mathrm{~mm}$, between dashed and solid lines). Shading and error bars indicate the 5th percentile, mean, and 95th percentile by functional group (black: flagellates, light gray: diatoms, white: microzooplankton, dark gray: mesozooplankton). Since slopes were calculated from the ratio of mesozooplankton to the other groups, the dark gray area precisely follows the solid line

Table 2). Binned by NBSS slope, the greatest contribution to total biomass was at steep slopes for diatoms, at intermediate slopes for microzooplank- 
Table 2. Theoretical distribution of plankton biomass among size ranges at different normalized biomass size spectrum slopes and binned mean (SD) of modeled distribution among functional groups, in percent

\begin{tabular}{|c|c|c|c|c|c|c|c|c|}
\hline \multirow[t]{2}{*}{ Slope } & \multicolumn{3}{|c|}{ Theoretical $^{\mathrm{a}}$} & \multicolumn{4}{|c|}{ ECOHAM, binned ${ }^{b}$ by dynamic size spectrum model slope } & \multirow[t]{2}{*}{$\mathrm{N}$} \\
\hline & Nano & Micro & Meso & Flagellates & Diatoms & Microzoo & Mesozoo $^{c}$ & \\
\hline-1.6 & 96.8 & 3.1 & 0.1 & & & & & \\
\hline-1.5 & 94.4 & 5.3 & 0.3 & & & & & \\
\hline-1.4 & 90.0 & 9.0 & 1.0 & $31.2(4.5)$ & $65.4(4.6)$ & $1.8(0.2)$ & $1.6(0.1)$ & 454 \\
\hline-1.3 & 82.3 & 14.6 & 3.1 & 35.1 (8.6) & $54.4(9.1)$ & $6.7(2.4)$ & $3.8(1.0)$ & 30533 \\
\hline-1.2 & 69.1 & 21.8 & 9.1 & $36.0(8.9)$ & $29.1(12.6)$ & $23.4(5.4)$ & $11.5(2.6)$ & 341167 \\
\hline-1.1 & 48.6 & 27.3 & 24.0 & 33.8 (10.3) & $20.2(7.7)$ & $27.8(6.3)$ & $18.3(3.6)$ & 161360 \\
\hline-1.0 & 25.0 & 25.0 & 50.0 & $34.6(5.0)$ & $13.9(4.1)$ & $7.7(4.2)$ & $43.8(6.4)$ & 4081 \\
\hline-0.9 & 8.6 & 15.4 & 76.0 & $28.1(1.7)$ & $5.1(0.9)$ & $2.3(0.6)$ & $64.5(0.3)$ & 5 \\
\hline-0.8 & 2.2 & 6.9 & 80.9 & & & & & \\
\hline \multicolumn{9}{|c|}{${ }^{\mathrm{a} E q}$ (A6) in the Appendix (adapted for nano- and microplankton) } \\
\hline${ }^{\mathrm{c}}$ Devia & ns from & heoretic & eso & tin & hing & & & \\
\hline
\end{tabular}

ton, and (by design) at shallow slopes for mesozooplankton. The flagellate contribution appeared to be independent of NBSS slope (Fig. 2).

A succession in plankton productivity was apparent, in which the annual increase in mesoplankton lagged behind that of the other groups, and NBSS slopes were consequently steeper from February through May (with a minimum in April) than during the rest of the year (Fig. 3). Prey field conditions for young cod larvae were much more variable in terms of both biomass and NBSS slope than for anchovy larvae (Fig. 3). Seasonal patterns varied by location and year, but the NBSS slope was generally steeper in the northwest in spring and shallower in the southeast in summer (Fig. 4).

\section{Larval fish growth and survival}

Modeled cod larvae exhibited positive growth in $83 \%$ of the cases $(n=224000$ combinations of location, year, and month). In the remaining cases, larvae failed to gain mass either due to inadequate prey resources (February through April) or because temperatures surpassed their thermal tolerance limit (in June). Potential foraging success ranged from 14 to $430 \%$ (median $160 \%$ ) of the potential limit established by digestion rate. Cod growth rates had unimodal dis-
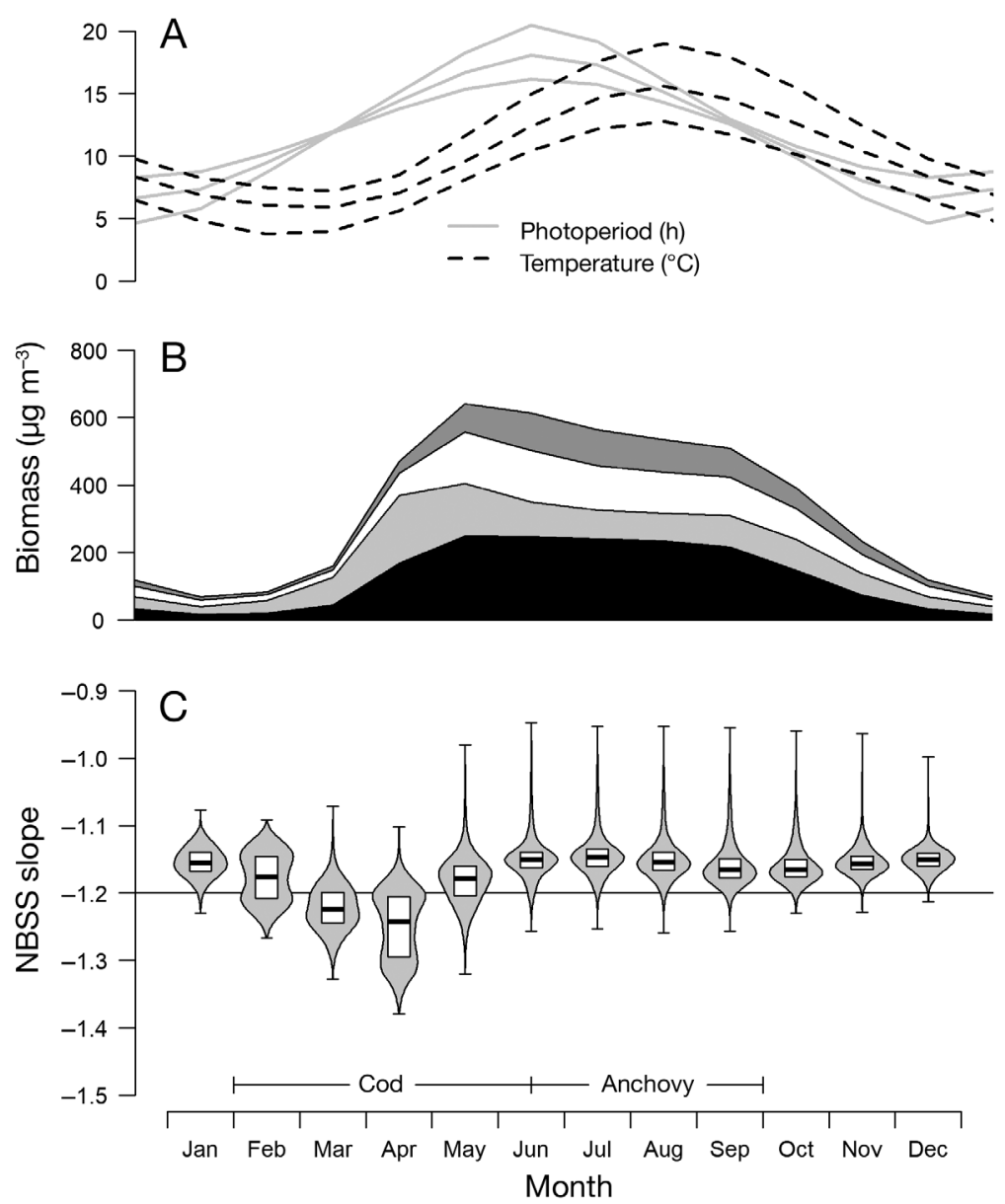

Fig. 3. Seasonal patterns of modeled North Sea ecosystem from 1970-2009 at 0-15 m depth. (A) Mean, 5th, and 95th percentile of temperature and photoperiod. (B) Mean biomass of flagellates (black), diatoms (light gray), microzooplankton (white), and mesozooplankton (dark gray). (C) Minimum, 25th percentile, median, 75th percentile, maximum, and smoothed density distribution of normalized biomass size spectrum (NBSS) slopes. The periods when $7 \mathrm{~mm}$ cod and $5.5 \mathrm{~mm}$ anchovy larvae are likely to occur in the North Sea are shown 


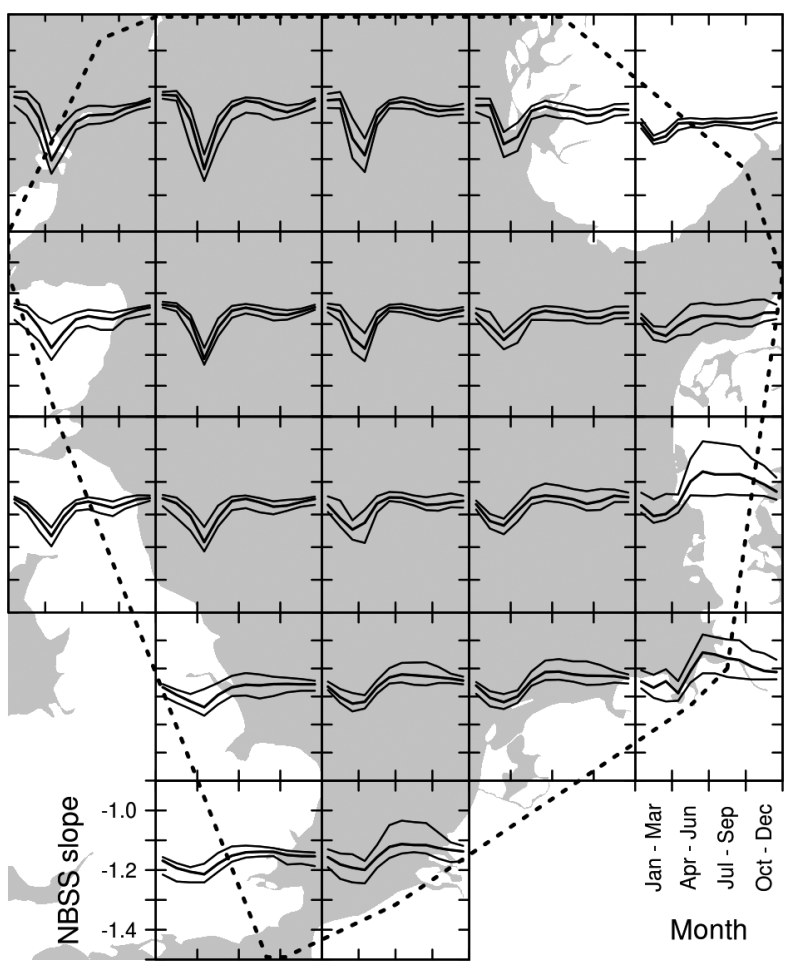

Fig. 4. Spatiotemporal dynamics of modeled normalized biomass size spectrum (NBSS) slopes in the North Sea (monthly means for 0-15 m depth, 20 km horizontal resolution, 19702009). Each time-series shows the 5th percentile, mean, and 95th percentile of NBSS slopes inside the respective spatial box. Mercator (equal-angle) map projection. Dashed line: model domain

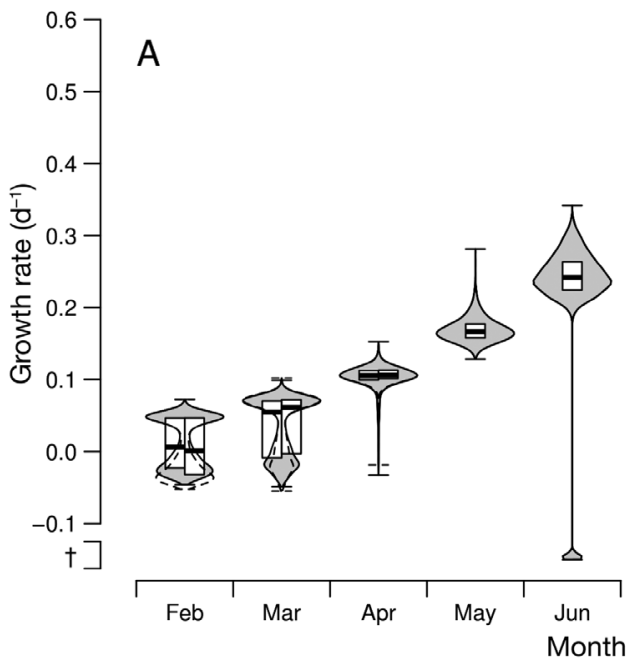

B
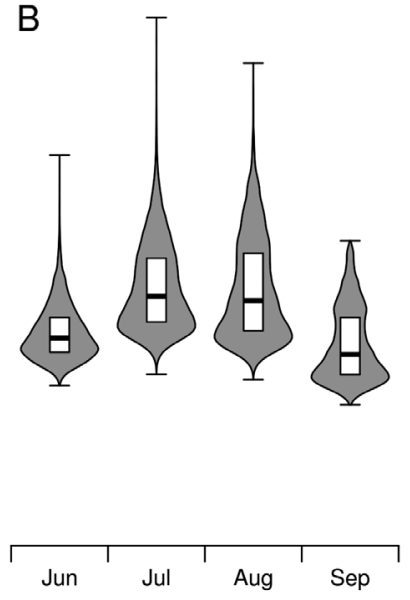

Fig. 5. Seasonal patterns in modeled growth rates of (A) $7 \mathrm{~mm}$ cod and (B) $5.5 \mathrm{~mm}$ anchovy larvae the North Sea. Simulations were conducted for 1970-2009 using coupled ecosystem, prey biomass size spectrum, and individual-based fish models. For each month, the results for 1120 spatial grid-cells $\times 40 \mathrm{yr}=44800$ larvae are summarized by their minimum, 25th percentile, median, 75th percentile, maximum, and smoothed density distribution. Where differences arose from using a fixed normalized biomass size spectrum slope of -1.2 (dashed shape, right box) instead of the dynamic prey biomass size spectrum model (solid shape, left box), both are shown. $\uparrow$ : death by exposure to high temperatures tributions in April and May and bimodal distributions in February, March, and June, with one mode corresponding to positive growth and the other to starvashifting shape of the distribution, the median across the Dogger Bank to the Skagerrak (Fig. 6).

teled growth of young anchovy larvae was 179200), limited by sub-optimal temperatures res ing in slow digestion, as opposed to foraging. Potential foraging success was always $>180 \%$ of potential digestion rate. Growth rates (median \pm inter-quartile of anchovy larvae were substantially higher in (17 $\left.\pm 9 \% \mathrm{~d}^{-1}\right)$ and August $\left(16 \pm 11 \% \mathrm{~d}^{-1}\right)$ than in June $\left(11 \pm 5 \% d^{-1}\right)$ or September $\left(10 \pm 9 \% d^{-1}\right)$ (Fig. 5). This temporal pattern was entirely driven by seasonal changes in temperature and photoperiod. Median water temperature was lowest in June $\left(12^{\circ} \mathrm{C}\right)$, peaked in August $\left(15^{\circ} \mathrm{C}\right)$, and was similar in July and September $\left(14^{\circ} \mathrm{C}\right)$, whereas photoperiod declined from June (18 h) to July $(17 \mathrm{~h})$ to August (15 h) to September $(13 \mathrm{~h})$. Median growth rate by location (pooled from June to September) followed a gradient from $<10 \%$ $\mathrm{d}^{-1}$ in the northwest to $>20 \% \mathrm{~d}^{-1}$ in the southeast (Fig. 7).

\section{Juvenile recruitment}

There were significant positive associations between median larval growth rates and both raw and detrended juvenile recruitment indices (Table 3 , Figs. 8-10). In cod, this relationship was strongest using median larval growth rates for February (Fig. 9), weaker in March, and switched to a 


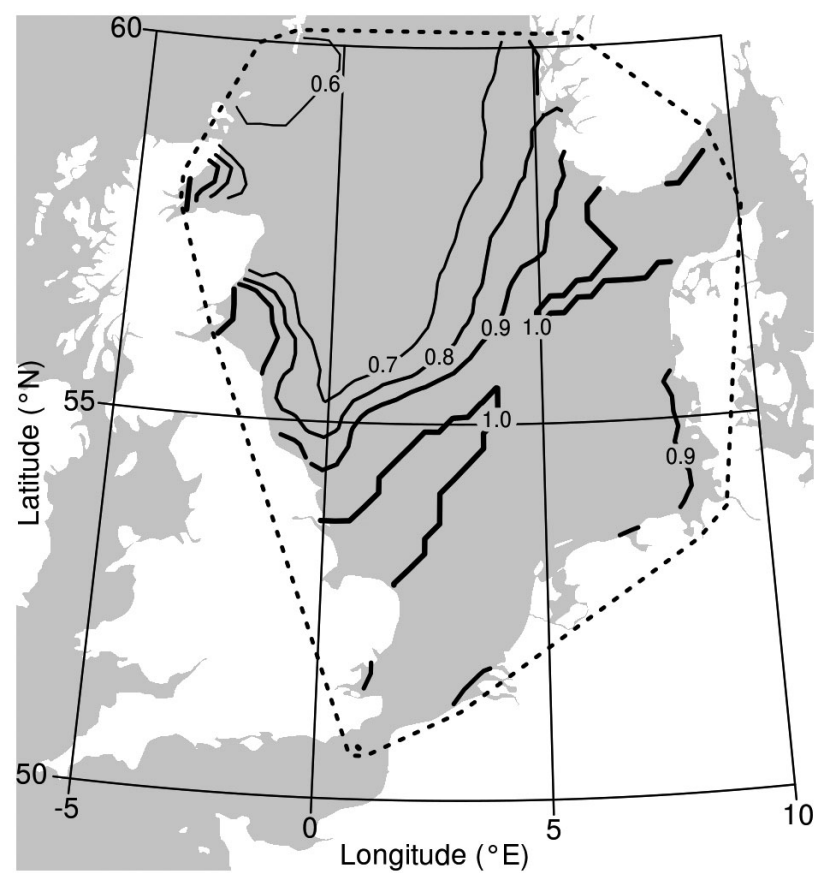

Fig. 6. Mean survival of modeled $7 \mathrm{~mm}$ cod larvae in the North Sea for February-June of 1970-2009. In the northwest, larvae frequently experienced foraging conditions insufficient for positive growth. In the southeast, larvae sometimes experienced temperatures above their thermal tolerance. Albers (equal-area) map projection. Dashed line: model domain

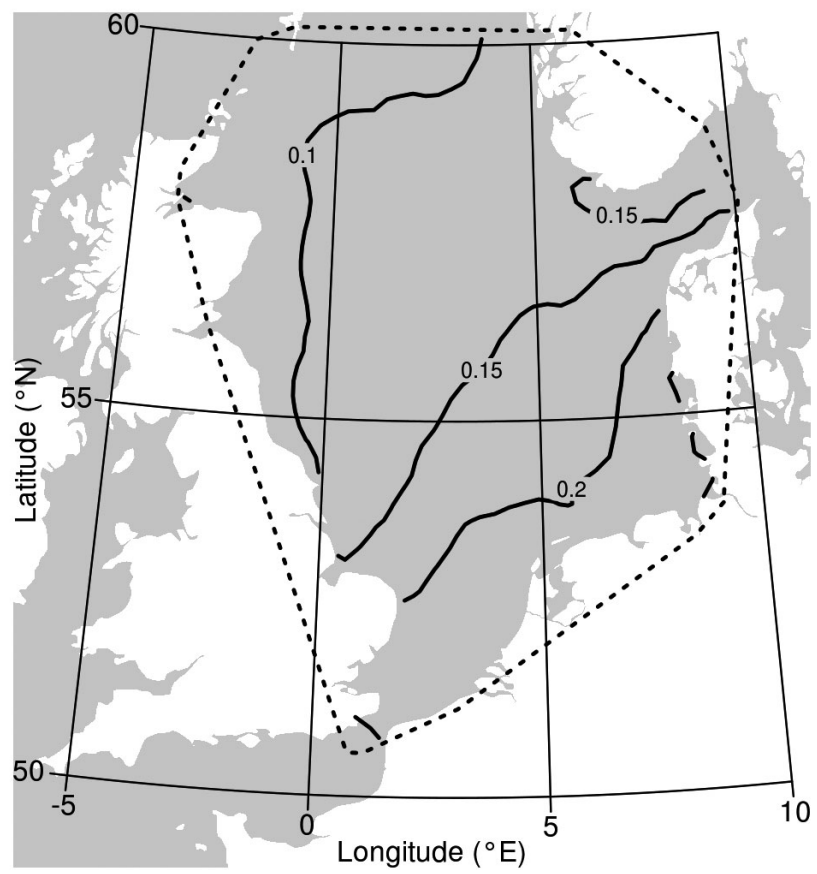

Fig. 7. Mean modeled dry mass growth rate $\left(\mathrm{d}^{-1}\right)$ of $5.5 \mathrm{~mm}$ anchovy larvae in the North Sea for July-September of 19702009. Albers (equal-area) map projection. Dashed line: model domain negative association from April to June (Table 3). In anchovy, the association was strongest for August (Fig. 10) and weakest for June (Table 3). Since our detrending procedure (Fig. 8) smoothed the raw recruitment signal for any given year beyond exclusively removing the influence of other years, we consider $22 \%$ for February cod and $42 \%$ for August anchovy larvae to be conservative (low) estimates for the actual effect (rank correlation) of early larval growth on juvenile recruitment. In both species, instances of high (fourth quartile) and low (first quartile) larval growth rates were good predictors of positive and negative detrended recruitment, respectively (cod: $75 \%$ accuracy, binomial test $\mathrm{p}=0.006$; anchovy: $90 \%$ accuracy, p < 0.001). Larval cod mortality due to lethal June temperatures was not significantly correlated with recruitment (tau $=-11 \%, p>$ 0.05).

\section{Dynamic prey size distributions}

Simulations substituting static prey size distributions with slopes of -1.2 for the dynamic size spectrum model resulted in some differences in growth and survival for cod larvae, but none for anchovy. With a fixed slope of -1.2 , food limitation of cod larvae was slightly more severe in February and slightly less so in March (Table 3, Fig. 5). Rank correlations among median larval growth rates and lagged juvenile recruitment were much lower for March but otherwise similar (Table 3). All model output for anchovy was identical with or without the dynamic size spectrum model, as larval growth was never food-limited.

\section{DISCUSSION}

\section{Model skill}

Our modeled growth rates were in good agreement with the few available empirical growth estimates for young European anchovy and Atlantic cod larvae in the North Sea. Kanstinger \& Peck (2009) used a biochemical (RNA:DNA) method to estimate a median mass-specific growth rate of $21 \% \mathrm{~d}^{-1}$ for 5.6 to $10.3 \mathrm{~mm}$ anchovy larvae (their Fig. 6, converted from instantaneous to daily proportional growth rate). The majority of their larvae were collected on 1 July 2005 at $53.74^{\circ} \mathrm{N}, 7.16^{\circ} \mathrm{W}$ in the Wadden Sea. Our prediction for the same place and time (interpolated) was $23 \% \mathrm{~d}^{-1}$. Based on SL and otolith-derived age, 
Table 3. Rank correlation (Kendall's tau) of modeled monthly median larval fish growth and subsequent juvenile recruitment (raw and detrended data from the first quarter of the North Sea International Bottom Trawl Survey). NBSS: normalized biomass size spectrum. Bold: $\mathrm{p}<0.05$

\begin{tabular}{|c|c|c|c|c|c|c|c|c|c|c|}
\hline NBSS slope & Recruitment & & & Cod & & & & nchor & & \\
\hline & index & Feb & Mar & Apr & May & Jun & Jun & Jul & Aug & Sep \\
\hline Dynamic & Raw & 0.34 & 0.20 & -0.30 & -0.37 & -0.33 & 0.27 & 0.50 & 0.59 & 0.59 \\
\hline Dynamic & Detrended & 0.22 & 0.17 & -0.09 & -0.10 & -0.18 & 0.03 & 0.31 & 0.42 & 0.28 \\
\hline Static $(-1.2)$ & Raw & 0.33 & -0.07 & -0.31 & -0.37 & -0.33 & 0.27 & 0.50 & 0.59 & 0.59 \\
\hline Static $(-1.2)$ & Detrended & 0.24 & 0.02 & -0.10 & -0.10 & -0.18 & 0.03 & 0.31 & 0.42 & 0.28 \\
\hline
\end{tabular}

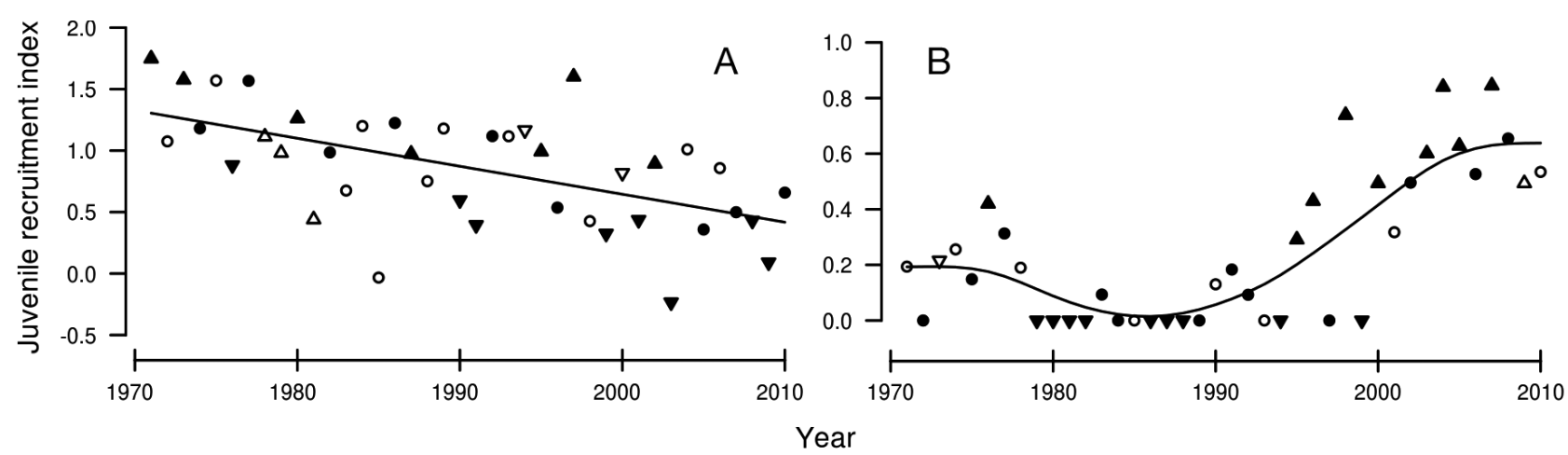

Fig. 8. Forty-year time series of (A) cod and (B) anchovy juvenile recruitment in the North Sea (indices calculated differently from NS-IBTS Q1 data, see Methods). Residuals of raw (symbols) versus smoothed (lines) values were used as detrended indices. Symbol shape indicates whether median modeled larval growth rates from the preceding February (cod) or August (anchovy) were relatively low (10 inverted triangles), high (10 triangles), or intermediate (20 circles). Solid symbols indicate matches between larval growth and detrended juvenile recruitment (both high or both low) and open symbols indicate mismatches. The presence of high or low larval growth correctly predicted the sign of detrended juvenile recruitment in most cases (15 of 20 for cod, 18 of 20 for anchovy), while intermediate larval growth was a poor predictor ( 9 of 20 for cod, 12 of 20 for anchovy)

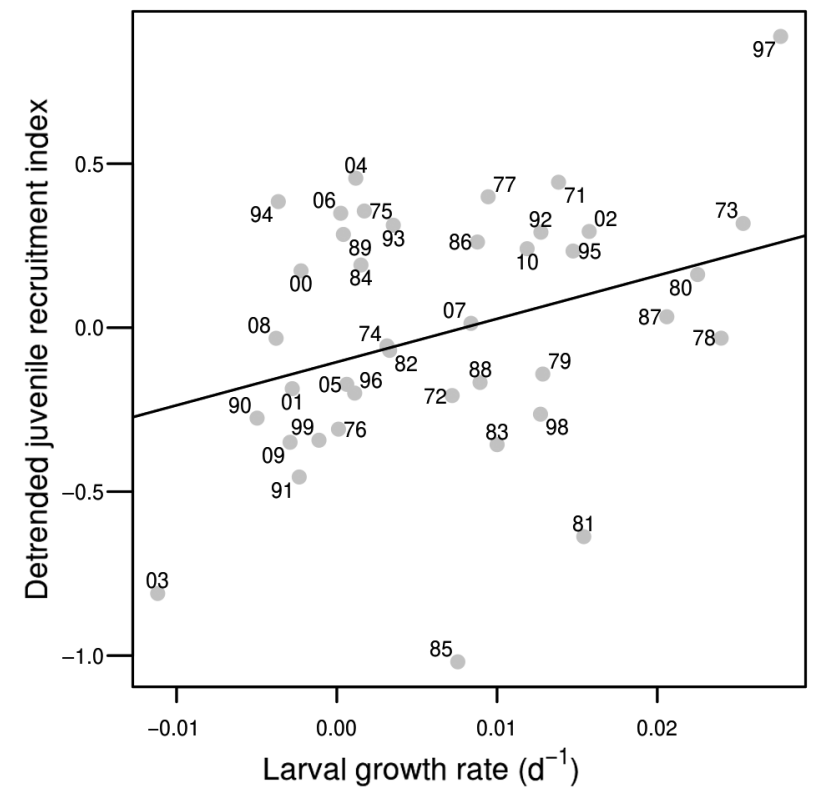

Fig. 9. Detrended first quarter 1971-2010 juvenile cod recruitment in the North Sea was positively associated with modeled median larval growth rates for February 19702009. The Kendall robust line fit illustrates a $22 \%$ rank-correlation $(\mathrm{p}=0.048)$, and is not intended to suggest a strictly linear relationship

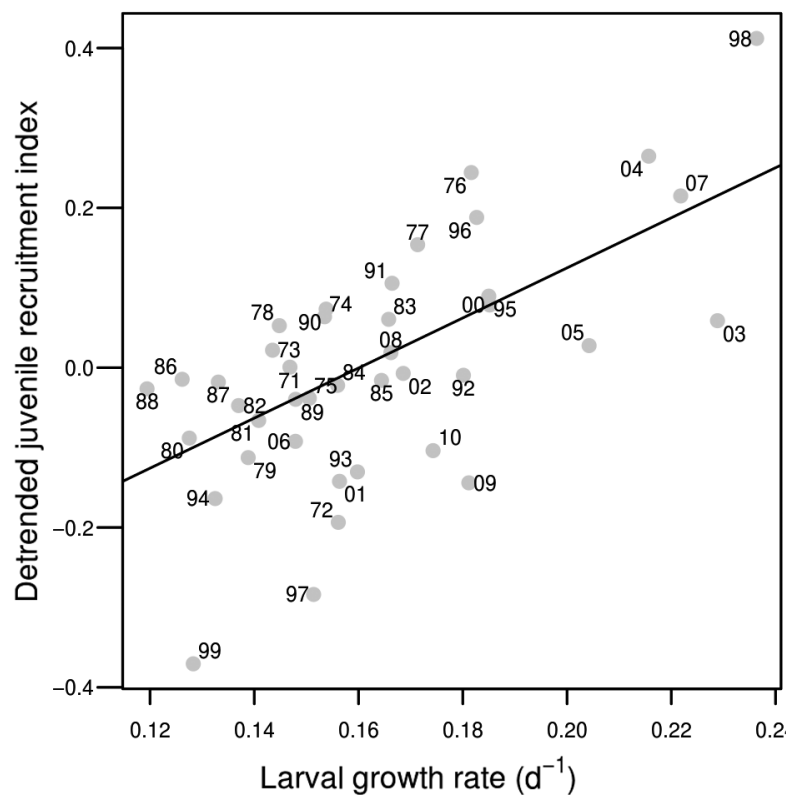

Fig. 10. Detrended first quarter 1971-2010 juvenile anchovy recruitment was positively associated with modeled median larval growth rates for August 1970-2009. The Kendall robust line fit illustrates a $42 \%$ rank-correlation $(p=0.001)$, and is not intended to suggest a strictly linear relationship 
Nielsen \& Munk (2004) estimated that $7 \mathrm{~mm}$ larval cod obtained growth rates of $0.22 \mathrm{~mm} \mathrm{~d}^{-1}$ (interpolated from their Table 1). Their larvae were sampled in the north-eastern North Sea $\left(\sim 56-57^{\circ} \mathrm{N}\right.$ and $6-8^{\circ} \mathrm{W}$ ), and individuals $<9 \mathrm{~mm}$ were primarily collected in April 2001. Our mean April 2001 growth rate for $7 \mathrm{~mm}$ cod in the same area was $0.23 \mathrm{~mm} \mathrm{~d}^{-1}$. In both cases, modeled growth was limited by temperature-dependent digestion, and not by the amount of suitably sized prey. Modeled prey concentrations were more than twice as high as necessary for the observed growth rates. In previous Quirks validation experiments, which compared modeled growth rates with estimates from laboratory and field studies, model predictions for both food-limited and 'satiated' larvae were similarly accurate, with mean prediction errors of $5 \% \mathrm{~d}^{-1}$ (Huebert \& Peck 2014). These comparisons included mimicking a study by Caldarone et al. (2003), in which cod larvae were fed different rations of wild plankton. Modeled growth rates for unfed larvae and larvae fed high rations were all within $3 \% \mathrm{~d}^{-1}$ of the range observed in the laboratory (Caldarone et al. 2003, Huebert \& Peck 2014). For larvae fed low rations, model predictions fell almost $7 \% \mathrm{~d}^{-1}$ below the empirical range, possibly due to an inaccurate representation of laboratory rations in terms of model parameters. Rigorously validating our coupled modeling approach will require far more empirical data, including samples of larvae experiencing a broad range of foraging conditions in the field.

\section{Cod recruitment in the North Sea}

The cod stocks of the North Sea have been in decline for decades, due to a combination of high fishing pressure and low juvenile recruitment (Fig. 9). Several previous studies have reported links between poor recruitment of cod and processes associated with poor foraging and slow growth of larvae in the North Sea. Beaugrand et al. (2003) compared zooplankton data (from the continuous plankton recorder survey) to cod recruitment (modeled by a virtual population analysis). They found that variability in larval prey field characteristics, particularly the abundance of Calanus finmarchicus, was positively associated with cod recruitment (rank correlation Kendall's tau $=0.23$ for 1958-1999 data detrended by our method) and attributed low recruitment to food limitation of late larvae and early juveniles. Using similar datasets, Beaugrand \& Kirby (2010) and Olsen et al. (2011) presented circumstantial evidence for a direct, causal link between plankton and cod recruitment, in addition to the direct and indirect effects of temperature and spawning stock biomass. In our study, food-limited growth of virtual larvae $\sim 7 \mathrm{wk}$ younger than inferred by Beaugrand et al. (2003) predicted a similar amount of variability in recruitment $(\operatorname{tau}=0.22$ for detrended 1970-2009 data). Daewel et al. (2015) modeled the growth, survival, and passive advection of cod early life history stages from fertilization up to $20 \mathrm{~mm} \mathrm{SL}$, a size between our young larvae and the life stages highlighted by Beaugrand et al. (2003). A similar correlation was apparent, this time between survival to $20 \mathrm{~mm}$ and virtual population analysis recruitment (tau $=0.17$ for 1958-2002 data detrended by our method). Daewel et al. (2015) noted that their correlation was strongly positive in the late 1960s and in the 1990s but negative in the 1980s. They hypothesized that periods when early life history processes were particularly important had alternated with periods when other factors (e.g. fishing pressure) were more influential. Our approach of modeling monthly growth snapshots, instead of tracking survival over time, revealed a similar pattern of multi-decadal variability. The association between larval growth in February and lagged, detrended NS-IBTS Q1 juvenile recruitment was strongest for the 2000s (tau $=0.56$ ), weaker for the 1990s and 1970s (tau $=0.29$ ), and negative for the $1980 \mathrm{~s}(\mathrm{tau}=-0.24)$.

A few studies have modeled both bottom-up and top-down effects on cod early life history stages in the North Sea. Kristiansen et al. (2011) modeled $30 \mathrm{~d}$ of larval growth and survival starting from the time of first feeding and included size-dependent, temperature-independent predation mortality. Their main finding was that bottom-up effects associated with cumulative temporal overlap between larvae and prey had a strong influence on survival. Akimova et al. (2016) modeled the cumulative predation mortality of cod from spawning through the first year of life, with a particular focus on the interplay between growth-potential and predation, both of which increased with increasing temperature. By comparing modeled size distributions of virtual juveniles to those obtained from the IBTS Q1 for 1991 to 2010, they inferred that the realized growth of survivors until age 1 was above $75 \%$ of growth-potential, and closer to $100 \%$ than to $75 \%$. Our results for $7 \mathrm{~mm}$ larvae are in close agreement with this finding. Pooled by month, our mean $\pm \mathrm{SD}$ of positive growth rates (i.e. survivors) was $83 \pm 2 \%$ (February), $81 \pm 3 \%$ (March), $97 \pm 2 \%$ (April), and 100\% (May and June) of their respective growth potential. For all survivors 
combined, growth rates were $92 \pm 9 \%$ of growth potential. Interestingly, model output from both Kristiansen et al. (2011) and Akimova et al. (2016) showed better cod survival and recruitment in warmer years, which is at odds with our results, IBTS recruitment data, and previous studies that omitted predation (Beaugrand et al. 2003, Beaugrand \& Kirby 2010, Olsen et al. 2011, Daewel et al. 2015).

Our best model results, with respect to predicting juvenile cod recruitment, came from those simulations in which larval food limitation was most prevalent (Table 2). This further highlights the importance of prey fields to cod larvae both in models and in nature. February was the only month with consistently food-limited median growth rates, and the only month for which these were significantly $(p<0.05)$ associated with not just raw (tau $=0.34$ ), but also detrended (tau $=0.22$ ) recruitment. In the model, food limitation occurred in the majority of North Sea grid cells almost every year in February $(64 \pm 5 \%)$, around half of the time in March (52 $\pm 5 \%$ ), and not at all after that. In the real world, food limitation is likely to be even more prevalent, partly because of prey patchiness, and partly because winter ECOHAM plankton concentrations are known to overestimate field conditions (Pätsch \& Kühn 2008, Stegert et al. 2009). A secondary (more tentative) conclusion is that the earliest part of the spawning season may be particularly important in shaping cod recruitment success. The previously mentioned modeling study by Akimova et al. (2016) reached the opposite conclusion, and better field data will be required to resolve this question.

The observed seasonal reduction in food limitation occurred in synchrony with a change in the growth/ recruitment correlation, which became significantly $(\mathrm{p}<0.05)$ negative for April (tau $=-0.30)$, May (tau $=$ -0.37 ), and June (tau $=-0.33$ ) with respect to the raw recruitment index (Table 3). The factor linking these 2 patterns was modeled temperature. In the model, the metabolic rates of respiration and digestion predictably increased with temperature, but the benefit of faster digestion was conditional on a surplus of food (energy supply), while the cost of higher respiration (energy demand) was unavoidable. Early in the year, when food limitation was common, the cost of warm temperatures tended to outweigh the benefit. Later, as food limitation approached 0 , the net effect became positive. Consequently, both warm and cold years were likely to have opposite effects on winter and spring larval growth rates.

Interannual variability in food limitation was driven by potential digestion (a function of temperature), but to an even larger extent by potential foraging (a function of prey fields). Prey fields were also mechanistically linked to temperature, albeit much less directly, through the cumulative temperature effects on photosynthesis $\left(Q_{10}=1.5\right.$, Pätsch \& Kühn 2008) and thus primary and secondary productivity. Summarized as time series of monthly medians, larval cod growth was significantly $(p<0.05)$ correlated with potential foraging (and prey fields) in February (tau = 0.73 ) and March (tau $=0.74$ ) and with potential digestion (and temperature) in February (tau $=-0.55$ ) but not March (tau $=0.01$ ). The stronger and more prevalent association with foraging shows that modeled food limitation was not simply a proxy for temperature, and that modeled variability in prey fields was essential to our results.

\section{Anchovy recruitment in the North Sea}

Populations of anchovy species can display large recruitment fluctuations in response to bottom-up forcing such as changes in water temperature, wind patterns, or plankton dynamics (MacCall 2009, Lindegren et al. 2013). Historically, European anchovy have sometimes flourished and sometimes virtually disappeared from the North Sea (Aurich 1953, Alheit et al. 2012, Petitgas et al. 2012) and, following a decade of very low abundance in the 1980s, anchovy increased in number since the early 1990s (Beare et al. 2004) (Fig. 8). Previous studies have shown a strong association between climate and the size of the European anchovy population in the North Sea, with periods of warmer water being favorable (Alheit et al. 2012, Petitgas et al. 2012).

Increased thermally suitable spawning habitat and increased growth and survival of early life history stages are 2 likely mechanisms for the positive association among North Sea temperature and anchovy recruitment. Since our modeled prey fields always exceeded the ad libitum feeding requirements of simulated anchovy larvae, there was no decoupling between temperature and growth. Consequently, the rank-correlation with lagged recruitment was equal for growth and for temperature. We can use this to infer whether larval growth or adult spawning is likely to be more important. Based on egg, larval, and adult surveys in the German Bight, anchovy spawning peaks in June and July with little to no spawning in August (Aurich 1953, Vorberg 2003). In our data, the association among monthly average temperature or growth and lagged recruitment is weak in June, peaks in August, and continues 
through at least September (Table 3). This temporal pattern matches the occurrence of young larvae much better than it matches adult spawning and, thus, provides circumstantial evidence that temperature primarily influences recruitment via growth and survival processes during the early larval period.

Raab et al. (2013) used 2 different approaches to study growth and survival of anchovy larvae and juveniles in the North Sea. Statistical models of juvenile recruitment (1973-2006 IBTS Q1 data) as a function of lagged sea surface temperature (NOAA data) and zooplankton (continuous plankton recorder survey data) detected a significant temperature effect but no significant zooplankton effect (Raab et al. 2013). Raab et al. (2013) also used a dynamic energy budget model coupled to a spatially explicit NPZ+ model (GETM-ERSEM) to estimate the proportion of the North Sea supporting the growth required for $5 \mathrm{~mm}$ larvae on 1 June to become $10 \mathrm{~cm}$ juveniles by 31 December (with a fixed fraction of zooplankton production available to anchovy). This temporally integrated metric was similarly predictive of juvenile recruitment as our July or August snapshots of median growth/temperature $(\operatorname{tau}=0.61$ for 1985-2007, no detrending). This further strengthens the view that temperature effects are of greatest importance for young anchovy larvae.

\section{Dynamic prey size distributions}

When Platt \& Denman $(1977,1978)$ first introduced the NBSS concept $\sim 40$ yr ago, they predicted a slope of -1.22 for steady-state pelagic ecosystems. Since then, a value of -1.2 has been an essential reference point for empirical and theoretical work on biomass size spectra (Kerr \& Dickie 2001), including advances related to the metabolic theory of ecology (Brown \& Gillooly 2003, Jennings \& Mackinson 2003). Jennings \& Mackinson (2003) reported a slope of -1.2 specifically for the North Sea ecosystem, based on samples of invertebrates and fish. Our modeled mean NBSS slope of -1.17 is consistent with the aforementioned studies, lending support to the approach of imposing explicit size structure on NPZ+ model functional groups for the purpose of generating prey fields for higher-level consumers.

Changes in plankton biomass composition from steep to shallow NBSS slopes matched theoretical expectations in the sense that mesozooplankton increased (by design), microzooplankton peaked at an intermediate slope of -1.125 (near the theoretical value of -1.07 for all microplankton), and total phyto- plankton decreased (Table 2, Fig. 2; Eq. A6 adapted for microplankton). The major inconsistency was that flagellates made up a much smaller than expected fraction of phytoplankton biomass, especially at steep slopes (Fig. 2). This means that the ECOHAM output used as input to the size spectrum model was apparently dominated by microplankton (mean $28 \%$ diatoms plus $24 \%$ microzooplankton), while a maximum of only $\sim 28 \%$ is theoretically possible in our NBSS slope framework (Fig. 2, Table 2, Appendix). Several factors may contribute to this discrepancy. ECOHAM functional groups are defined by biogeochemical and trophic relationships, not size. Consequently, nominal ECOHAM microzooplankton should be interpreted as including heterotrophic flagellates $<0.02 \mathrm{~mm}$, which can form the majority of nanoplankton biomass (Nielsen et al. 1993). Similarly, a small fraction of diatoms may represent nanoplanktonic species, which can be seasonally abundant in the North Sea (Hoppenrath et al. 2007). Moreover, mixotrophs and photosynthetic picoplankton are not represented in ECOHAM, and it is possible that the model captures or compensates for their trophic roles by overrepresenting microzooplankton and diatoms.

Nevertheless, plankton communities with high microplankton fractions have been observed in the North Sea. For example, Riegman et al. (1993) sampled pico- through mesozooplankon in Dutch coastal waters from February to April 1992. For much of this time, microplankton apparently accounted for more than half of the total plankton biomass (Riegman et al. 1993). Other field data are more consistent with biomass as distributed by our size spectrum model than with the underlying ECOHAM output. Nielsen et al. (1993) used May/June 1990 field samples to calculate carbon budgets for 4 different regions of the southern central North Sea. In these carbon budgets, slightly less than $19,28,29$, and $38 \%$ of the biomass of combined nano- through mesoplankton consisted of microplankton (Nielsen et al. 1993). The 3 lower values match the $18-28 \%$ microplankton range that was predicted $95 \%$ of the time by our size spectrum model, while the higher value was driven by excess heterotrophic dinoflagellates and not diatoms.

Besides yielding more dynamic prey fields, carrying over variability in biomass distribution from NPZ+ functional groups to dynamic NBSS slopes also requires fewer simplifying assumptions than alternative approaches such as applying a constant NBSS slope or a similar reference point based on field samples (Daewel et al. 2008a, 2015). All 3 approaches assume (1) an idealized allometric scaling relationship between plankton size and mass in order to model 
predator-prey interactions, and (2) lower and upper size limits for NPZ+ functional groups, in order to separate potential prey biomass among smaller size bins. Taking further advantage of these 2 key assumptions to calculate NBSS slopes avoids the unrealistic oversimplification of spatiotemporally static size spectra and additional assumptions involved in defining this shape (e.g. by 1 NBSS slope). While there is some evidence for a mean North Sea NBSS slope of -1.2 (Jennings \& Mackinson 2003), we preferred to see whether this number would emerge as a result of our study rather than fixing it as an a priori assumption. Avoiding this assumption only made a small difference for cod and no difference for anchovy growth rates in the present study. This seems to suggest that the dynamic size spectrum model did not turn out to be practically necessary. Whether or not the same holds true for other species and systems, coupling models via dynamic NBSS slopes is internally more consistent (NPZ+ variability is propagated), technically more conservative (fewer assumptions are required), and potentially more realistic (e.g. spring bloom dynamics are represented, Figs. 3 \& 4).

Field samples of plankton provide better information on larval fish prey fields than any available model and their spatiotemporal coverage has sometimes been sufficient for use in larval fish modeling studies. In an example for the North Sea, Kühn et al. (2008) modeled the foraging, growth, and drift of European sprat larvae in the German Bight in 2004. Unfortunately, the limited coverage and potential sampling biases of field samples are problematic for drawing conclusions on an ecosystem-wide or multidecadal scale. We know that prey size distributions vary in time and space, thus defining any one static distribution (Daewel et al. 2008a, 2015) may lead to spurious results and interpretations of seasonal growth patterns. However, despite extensive field sampling in the North Sea (e.g. Fransz et al. 1991, Nielsen et al. 1993, Munk 2007, Kühn et al. 2008), we still lack sufficient understanding of plankton dynamics (and climate effects) to confidently assume specific patterns of variation (spatial or temporal) in plankton size distributions. Our method avoids this conundrum by relying on the same NPZ+ model output to estimate both low-resolution plankton biomass as well as, subsequently, high-resolution plankton size distribution dynamics. Finally, the spatiotemporal patterns in modeled NBSS slope can serve as testable hypotheses for future fieldwork with acoustic or optical plankton sampling instruments (e.g. Vandromme et al. 2014).

\section{Conclusions}

Simulating fish early life history by using coupled, mechanistic models is a promising approach for studying and predicting ecosystem-wide patterns in fish recruitment. One major challenge is that models for ecosystem biogeochemistry and for larval fish foraging represent plankton in fundamentally different ways. Bulk phytoplankton and zooplankton concentrations are not necessarily good proxies for the plankton size ranges that are actually important for fish larvae and using such proxies can lead to large uncertainties in foraging models (Bils et al. 2017). Our new size spectrum model provides high-resolution, dynamic estimates of size-structured prey fields from bulk plankton groups that are commonly available in NPZ+ models. The size spectrum model thus allows straightforward 1-way (bottom-up) coupling to fish models without relying on additional, poorly constrained field parameters of prey size distribution. The method can be adapted for different numbers of NPZ+ groups, as long as it is possible to estimate plankton biomass for 2 or more different size ranges.

To test our new method and its versatility, we performed $40 \mathrm{yr}$ hindcast simulations for young larvae of 2 fundamentally different fish species coexisting in the North Sea. In both cases, modeled larval growth rates were comparable to available field observations. Further, interannual variability in growth rates was significantly predictive of juvenile recruitment indices, consistent with the expectation that fast growth generally enhances larval survival. Food limitation played a substantial role in determining larval cod growth rates, while larval anchovy were never subject to food limitation.

Extending this approach to include larval transport or mortality from realistic predator fields will facilitate comparisons of the strength of these processes affecting the larvae of these and other species.

Acknowledgements. Funding for this research was provided by the EU 7th Framework Programme grants FACTS (Forage Fish Interactions, FP7 244966) and VECTORS (VECTORS of Change in Oceans and Seas Marine Life, Impact on Economic Sectors, FP7 266445), with additional support from the Cluster of Excellence CliSAP (Integrated Climate System Analysis and Prediction, EXC177), University of Hamburg, funded by the German Science Foundation (DFG). ECOHAM model simulations were conducted on 'Mistral,' the Atos bullx DLC B700 mainframe at the German Climate Computing Center (DKRZ) in Hamburg. Many thanks to ICES WGIPEM (Working Group on Modelling of Physical/Biological Interactions) for fruitful discussions. Insightful comments by the anonymous peer reviewers were greatly appreciated. 


\section{LITERATURE CITED}

Akimova A, Hufnagl M, Kreus M, Peck MA (2016) Modeling the effects of temperature on the survival and growth of North Sea cod (Gadus morhua) through the first year of life. Fish Oceanogr 25:193-209

Alheit J, Pohlmann T, Casini M, Greve W and others (2012) Climate variability drives anchovies and sardines into the North and Baltic Seas. Prog Oceanogr 96:128-139

Aurich HJ (1953) Verbreitung und Laichverhältnisse von Sardelle und Sardine in der südöstlichen Nordsee und ihre Veränderungen als Folge der Klimaänderung. Helgol Wiss Meeresunters 4:175-204

Backhaus JO (1985) A three-dimensional model for the simulation of shelf sea dynamics. Ocean Dyn 38:165-187

Beare DJ, Burns F, Greig A, Jones EG and others (2004) Long-term increases in prevalence of North Sea fishes having southern biogeographic affinities. Mar Ecol Prog Ser 284:269-278

Beaugrand G, Kirby RR (2010) Climate, plankton and cod. Glob Change Biol 16:1268-1280

Beaugrand G, Brander KM, Lindley JA, Souissi S, Reid PC (2003) Plankton effect on cod recruitment in the North Sea. Nature 426:661-664

Bils F, Moyano M, Aberle N, Hufnagl M, Alvarez-Fernandez S, Peck MA (2017) Exploring the microzooplanktonichthyoplankton link: a combined field and modeling study of Atlantic herring (Clupea harengus) in the Irish Sea. J Plankton Res 39:147-163

Brander K, Mohn R (2004) Effect of the North Atlantic Oscillation on recruitment of Atlantic cod (Gadus morhua). Can J Fish Aquat Sci 61:1558-1564

Brown JH, Gillooly JF (2003) Ecological food webs: Highquality data facilitate theoretical unification. Proc Natl Acad Sci USA 100:1467-1468

Caldarone EM, St Onge-Burns JM, Buckley LJ (2003) Relationship of RNA/DNA ratio and temperature to growth in larvae of Atlantic cod Gadus morhua. Mar Ecol Prog Ser 262:229-240

* Daewel U, Peck MA, Kühn W, Michael A, Alekseeva I, Schrum C (2008a) Coupling ecosystem and individualbased models to simulate the influence of environmental variability on potential growth and survival of larval sprat (Sprattus sprattus L.) in the North Sea. Fish Oceanogr 17:333-351

Daewel U, Peck MA, Schrum C, St John MA (2008b) How best to include the effects of climate-driven forcing on prey fields in larval fish individual-based models. J Plankton Res 30:1-5

Daewel U, Schrum C, Gupta AK (2015) The predictive potential of early life stage individual-based models (IBMs): an example for Atlantic cod Gadus morhua in the North Sea. Mar Ecol Prog Ser 534:199-219

Drinkwater KF (2005) The response of Atlantic cod (Gadus morhua) to future climate change. ICES J Mar Sci 62: $1327-1337$

Engelhard GH, Righton DA, Pinnegar JK (2014) Climate change and fishing: a century of shifting distribution in North Sea cod. Glob Change Biol 20:2473-2483

Fransz HG, Colebrook JM, Gamble JC, Krause M (1991) The zooplankton of the North Sea. Neth J Sea Res 28:1-52

Geffen AJ, Nash RD (2012) Egg development rates for use in egg production methods (EPMs) and beyond. Fish Res 117-118:48-62

Hay SJ, Evans GT, Gamble JC (1988) Birth, growth and death rates for enclosed populations of calanoid copepods. J Plankton Res 10:431-454
Hinckley S, Napp JM, Hermann AJ, Parada C (2009) Simulation of physically mediated variability in prey resources of a larval fish: a three-dimensional NPZ model. Fish Oceanogr 18:201-223

*Hobday AJ, Pecl GT (2014) Identification of global marine hotspots: sentinels for change and vanguards for adaptation action. Rev Fish Biol Fish 24:415-425

Hoppenrath M, Beszteri B, Drebes G, Halliger H, Beusekom JEEV, Janisch S, Wiltshire KH (2007) Thalassiosira species (Bacillariophyceae, Thalassiosirales) in the North Sea at Helgoland (German Bight) and Sylt (North Frisian Wadden Sea) - a first approach to assessing diversity. Eur J Phycol 42:271-288

KHoude ED (2008) Emerging from Hjort's shadow. J Northwest Atl Fish Sci 41:53-70

Huebert KB, Peck MA (2014) A day in the life of fish larvae: modeling foraging and growth using Quirks. PLOS ONE 9:e98205

Huthnance J, Weisse R, Wahl T, Thomas H and others (2016) Recent change - North Sea. In: Quante M, Colijn F (eds) North Sea Region Climate Change Assessment. Springer International Publishing, Cham, p 85-136

Jennings S, Mackinson S (2003) Abundance-body mass relationships in size-structured food webs. Ecol Lett 6: 971-974

Kanstinger P, Peck MA (2009) Co-occurrence of European sardine (Sardina pilchardus), anchovy (Engraulis encrasicolus) and sprat (Sprattus sprattus) larvae in southern North Sea habitats: abundance, distribution and biochemical-based condition. Sci Mar 73:141-152

Kerr SR, Dickie LM (2001) The biomass spectrum: a predator-prey theory of aquatic production. Columbia University Press, New York, NY

Kristiansen T, Drinkwater KF, Lough RG, Sundby S (2011) Recruitment variability in North Atlantic cod and matchmismatch dynamics. PLOS ONE 6:e17456

Kühn W, Peck MA, Hinrichsen HH, Daewel U and others (2008) Defining habitats suitable for larval fish in the German Bight (southern North Sea): an IBM approach using spatially-and temporally-resolved, size-structured prey fields. J Mar Syst 74:329-342

K Kühn W, Pätsch J, Thomas H, Borges AV, Schiettecatte LS, Bozec Y, Prowe AEF (2010) Nitrogen and carbon cycling in the North Sea and exchange with the North Atlantic a model study, Part II: carbon budget and fluxes. Cont Shelf Res 30:1701-1716

* Lindegren M, Checkley DM, Rouyer T, MacCall AD, Stenseth NC (2013) Climate, fishing, and fluctuations of sardine and anchovy in the California Current. Proc Natl Acad Sci USA 110:13672-13677

* Llopiz JK, Cowen RK, Hauff MJ, Ji R and others (2014) Early life history and fisheries oceanography: new questions in a changing world. Oceanography 27:26-41

Korkowski I, Pätsch J, Moll A, Kühn W (2012) Interannual variability of carbon fluxes in the North Sea from 1970 to 2006 - competing effects of abiotic and biotic drivers on the gas-exchange of $\mathrm{CO}_{2}$. Estuar Coast Shelf Sci 100:38-57

MacCall AD (2009) Mechanisms of low-frequency fluctuations in sardine and anchovy populations. In: Checkley DM Jr, Alheit J, Oozeki Y, Roy C (eds) Climate change and small pelagic fish. Cambridge University Press, Cambridge, p 285-299

*MacKenzie BR, Schiedek D (2007) Daily ocean monitoring since the 1860s shows record warming of northern European seas. Glob Change Biol 13:1335-1347

Menden-Deuer S, Lessard EJ (2000) Carbon to volume relationships for dinoflagellates, diatoms, and other protist 
plankton. Limnol Oceanogr 45:569-579

Munk P (2007) Cross-frontal variation in growth rate and prey availability of larval North Sea cod Gadus morhua. Mar Ecol Prog Ser 334:225-235

Munk P, Nielsen JG (2005) Eggs and larvae of North Sea fishes. Biofolia, Frederiksberg

Nielsen R, Munk P (2004) Growth pattern and growth dependent mortality of larval and pelagic juvenile North Sea cod Gadus morhua. Mar Ecol Prog Ser 278:261-270

Nielsen TG, Løkkegaard B, Richardson K, Pedersen FB, Hansen L (1993) Structure of plankton communities in the Dogger Bank area (North Sea) during a stratified situation. Mar Ecol Prog Ser 95:115-131

* Olsen EM, Ottersen G, Llope M, Chan KS, Beaugrand G, Stenseth NC (2011) Spawning stock and recruitment in North Sea cod shaped by food and climate. Proc R Soc B 278:504-510

Otterlei E, Nyhammer G, Folkvord A, Stefansson SO (1999) Temperature-and size-dependent growth of larval and early juvenile Atlantic cod (Gadus morhua): a comparative study of Norwegian coastal cod and northeast Arctic cod. Can J Fish Aquat Sci 56:2099-2111

* Ottersen G, Hjermann DØ, Stenseth NC (2006) Changes in spawning stock structure strengthen the link between climate and recruitment in a heavily fished cod (Gadus morhua) stock. Fish Oceanogr 15:230-243

Pätsch J, Kühn W (2008) Nitrogen and carbon cycling in the North Sea and exchange with the North Atlantic-a model study. Part I. Nitrogen budget and fluxes. Cont Shelf Res 28:767-787

* Peck MA, Hufnagl M (2012) Can IBMs tell us why most larvae die in the sea? Model sensitivities and scenarios reveal research needs. J Mar Syst 93:77-93

* Peck MA, Huebert KB, Llopiz JK (2012) Intrinsic and extrinsic factors driving match-mismatch dynamics during the early life history of marine fishes. Adv Ecol Res 47: $177-302$

* Perry AL (2005) Climate change and distribution shifts in marine fishes. Science 308:1912-1915

* Perry RI, Cury P, Brander K, Jennings S, Möllmann C, Planque B (2010) Sensitivity of marine systems to climate and fishing: concepts, issues and management responses. J Mar Syst 79:427-435

Petitgas P, Alheit J, Peck MA, Raab K and others (2012) Anchovy population expansion in the North Sea. Mar Ecol Prog Ser 444:1-13

Planque B, Fromentin JM, Cury P, Drinkwater KF, Jennings S, Perry RI, Kifani S (2010) How does fishing alter marine populations and ecosystems sensitivity to climate? J Mar Syst 79:403-417

Platt T, Denman K (1977) Organisation in the pelagic ecosystem. Helgol Mar Res 30:575-581

Platt T, Denman K (1978) The structure of pelagic marine ecosystems. Rapp PV Reun Cons Int Explor Mer 173:60-65

Pohlmann T (1996) Predicting the thermocline in a circulation model of the North Sea-Part I: model description, calibration and verification. Cont Shelf Res 16:131-146

Pohlmann T (2006) A meso-scale model of the central and southern North Sea: consequences of an improved resolution. Cont Shelf Res 26:2367-2385

Pörtner HO, Karl D, Boyd PW, Cheung W and others (2014) Ocean systems. In: Field CB, Barros VR, Dokken DJ, Mach KJ and others (eds) Climate change 2014: impacts, adaptation, and vulnerability. Part A: global and sectoral aspects. Contribution of Working Group II to the Fifth Assessment Report of the Intergovernmental Panel on Climate Change. Cambridge University Press, Cambridge, p 411-484

R Development Core Team (2016) R: a language and environment for statistical computing. R Foundation for Statistical Computing, Vienna

Raab K, Llope M, Nagelkerke LAJ, Rijnsdorp AD and others (2013) Influence of temperature and food availability on juvenile European anchovy Engraulis encrasicolus at its northern boundary. Mar Ecol Prog Ser 488:233-245

Regner S (1996) Effects of environmental changes on early stages and reproduction of anchovy in the Adriatic Sea. Sci Mar 60:167-177

* Riegman R, Kuipers BR, Noordeloos AAM, Witte HJ (1993) Size-differential control of phytoplankton and the structure of plankton communities. Neth J Sea Res 31: 255-265

Rijnsdorp AD, Peck MA, Engelhard GH, Möllmann C, Pinnegar JK (2009) Resolving the effect of climate change on fish populations. ICES J Mar Sci 66:1570-1583

* Rodriguez J, Jiménez F, Bautista B, Rodriguez V (1987) Planktonic biomass spectra dynamics during a winter production pulse in Mediterranean coastal waters. J Plankton Res 9:1183-1194

* Ruzicka JJ, Gallager SM (2006) The importance of the cost of swimming to the foraging behavior and ecology of larval cod (Gadus morhua) on Georges Bank. Deep Sea Res II 53:2708-2734

Schrum C, Lowe J, Meier HEM, Grabemann I and others (2016) Projected change - North Sea. In: Quante M, Colijn F (eds) North Sea region climate change assessment. Springer International Publishing, Cham, p 175-217

* Sheldon RW, Prakash A, Sutcliffe WH Jr (1972) The size distribution of particles in the ocean. Limnol Oceanogr 17: 327-340

* Sieburth JM, Smetacek V, Lenz J (1978) Pelagic ecosystem structure: heterotrophic compartments of the plankton and their relationship to plankton size fractions. Limnol Oceanogr 23:1256-1263

* Simpson SD, Jennings S, Johnson MP, Blanchard JL, Schön PJ, Sims DW, Genner MJ (2011) Continental shelf-wide response of a fish assemblage to rapid warming of the sea. Curr Biol 21:1565-1570

Stegert C, Moll A, Kreus M (2009) Validation of the threedimensional ECOHAM model in the German Bight for 2004 including population dynamics of Pseudocalanus elongatus. J Sea Res 62:1-15

Uye S, Sano K (1995) Seasonal reproductive biology of the small cyclopoid copepod Oithona davisae in a temperate eutrophic inlet. Mar Ecol Prog Ser 118:121-128

*Vandromme P, Nogueira E, Huret M, Lopez-Urrutia Á, González-Nuevo González G, Sourisseau M, Petitgas P (2014) Springtime zooplankton size structure over the continental shelf of the Bay of Biscay. Ocean Sci 10: 821-835

VLIZ (Vlaams Instituut voor de Zee) (2015) IHO sea areas, version 1. www.marineregions.org/downloads.php (accessed 3 June 2015)

Vorberg R (2003) Sardelle wieder im deutschen Wattenmeer heimisch. Fischerblatt 1:4-6

Xu Y, Chai F, Rose KA, Ñiquen CM, Chavez FP (2013) Environmental influences on the interannual variation and spatial distribution of Peruvian anchovy (Engraulis ringens) population dynamics from 1991 to 2007: a threedimensional modeling study. Ecol Model 264:64-82 
Appendix. Dynamic prey biomass size spectrum

Let $x$ be individual body dry mass and $f(x)$ be a biomass density function, meaning that the combined biomass $B_{a b}$ of all organisms in the interval $\mathrm{a} \leq x \leq b$ can be calculated by integration (Eq. A1):

$$
B_{a b}=\int_{b}^{a} f(x) d x
$$

We assume that our system conforms to a normalized biomass size spectrum slope $s$ (Platt \& Denman 1977, 1978). By definition, this means that a log-log plot of $f(x)$ must yield a straight line of slope $s$, and with a $y$-intercept that we will call $\log (c)$. A power function meets these conditions (Eq. A2):

$$
f(x)=C \cdot x^{S}
$$

Let mesoplankton and total plankton (i.e. pooled nano-, micro-, and mesoplankton) be defined by respective length ranges of $0.2-20 \mathrm{~mm}$ and $0.002-20 \mathrm{~mm}$ (Sieburth et al. 1978). To convert between length 1 in $\mathrm{mm}$ and mass $x$ in $\mu \mathrm{g}$ we use an empirical relationship (Eq. A3), fit to a broad range of plankton data (Hay et al. 1988, Uye \& Sano 1995, Menden-Deuer \& Lessard 2000, Ruzicka \& Gallager 2006):

$$
x=14 \cdot l^{2.5}
$$

We combine Eqs. (A1) through (A3) to express the biomass of mesoplankton (Eq. A4) and total plankton (Eq. A5) as functions of $S$ and $C$ :

$$
\begin{gathered}
B_{\text {meso }}=\int_{14 \cdot 0.2^{2.5}}^{14 \cdot 20^{2.5}} C \cdot x^{s} d x=\frac{C \cdot\left(14 \cdot 20^{2.5}\right)^{s+1}}{s+1}-\frac{C \cdot\left(14 \cdot 0.2^{2.5}\right)^{s+1}}{s+1} \\
B_{\text {total }}=\int_{14 \cdot 0.002^{2.5}}^{14 \cdot 20^{2.5}} C \cdot x^{s} d x=\frac{C \cdot\left(14 \cdot 20^{2.5}\right)^{s+1}}{s+1}-\frac{C \cdot\left(14 \cdot 0.002^{2.5}\right)^{s+1}}{s+1}
\end{gathered}
$$

Dividing Eq. (A4) by Eq. (A5) eliminates the constants $c$ and 14 (Eq. A6):

$$
r_{\text {meso }}=\frac{B_{\text {meso }}}{B_{\text {total }}}=\frac{\frac{C \cdot\left(14 \cdot 20^{2.5}\right)^{s+1}}{s+1}-\frac{C \cdot\left(14 \cdot 0.2^{2.5}\right)^{s+1}}{s+1}}{\frac{C \cdot\left(14 \cdot 20^{2.5}\right)^{s+1}}{s+1}-\frac{C \cdot\left(14 \cdot 0.002^{2.5}\right)^{s+1}}{s+1}}=\frac{20^{2.5 \cdot s+2.5}-0.2^{2.5 \cdot s+2.5}}{20^{2.5 \cdot s+2.5}-0.002^{2.5 \cdot s+2.5}}
$$

Eq. (A6) can be numerically solved for $S$, given any mesoplankton ratio $0<r_{\text {meso }}<1$, including 0.5 , where $s$ converges on -1 from both directions. Alternatively, Eq. (A7) gives an approximation for $s$ that is accurate to 4 decimals for $0.01<r_{\text {meso }}<$ 0.99:

$$
s \approx 0.08686 \cdot \ln \left(\frac{-r_{\text {meso }}}{r_{\text {meso }}-1}\right)-1
$$

Editorial responsibility: Alejandro Gallego, Aberdeen, UK
Submitted: August 8, 2017; Accepted: May 2, 2018

Proofs received from author(s): July 17, 2018 